\title{
Genetic Analysis of Indirect Selection for Winter Wheat Grain Yield Using Spectral Reflectance Indices
}

\author{
B. Prasad, B. F. Carver, M. L. Stone, M. A. Babar, W. R. Raun, and A. R. Klatt`
}

ABSTRACT

Selection criteria that can facilitate grain yield improvement would be considered important plant breeding tools. We assessed the value of spectral reflectance indices (SRI) as indirect selection tools for grain yield improvement in winter wheat (Triticum aestivum L.). The objectives of this study were to estimate genetic correlation between $\mathrm{SRI}$ and grain yield, heritability, response to selection, correlated response of grain yield, and relative selection efficiency of SRI for grain yield improvement. Three field experiments consisting of 25 winter wheat cultivars and 2 sets of 25 recombinant inbred lines were conducted in the Oklahoma State University Agronomy Farm for 2 yr. Eight SRI were calculated at three growth stages (booting, heading, and grain-filling). The water-based indices (water index and normalized water indices) showed moderate to high heritability and higher genetic correlations with grain yield compared to the commonly used vegetation-based indices (normalized difference vegetation index and simple ratio). The water-based indices also showed higher correlated response than direct response for grain yield. Up to $83 \%$ of the top $25 \%$ highest-yielding genotypes were selected by the two newly developed water-based indices (normalized water index 3 [NWI-3] and normalized water index 4 [NWI-4]). These results suggest the strong genetic basis of NWI-3 and NWI-4 as potential selection tools for winter wheat grain yield improvement under Great Plains conditions.
B. Prasad, B.F. Carver, W.R. Raun, and A.R. Klatt, Dep. of Plant and Soil Sciences, 368 Ag Hall, Oklahoma State Univ., Stillwater, OK 74078, USA; M.L. Stone, Dep. of Biosystems and Agricultural Engineering, Oklahoma State Univ., Stillwater, OK 74078, USA; M.A. Babar, Dep. of Agronomy, Kansas State Univ., Manhattan, KS 66506, USA. This research was partially funded by Oklahoma Agricultural Experiment Station, Oklahoma Wheat Commission, and Oklahoma Wheat Research Foundation. Received 28 Aug. 2006. *Corresponding author(art.klatt@okstate.edu).

Abbreviations: GNDVI, green normalized difference vegetation index; NWI, normalized water indices; NWI-1, normalized water index 1; NWI-2, normalized water index 2; NWI-3, normalized water index 3; NWI-4, normalized water index 4; RNDVI, red normalized difference vegetation index; SR, simple ratio; SRI, spectral reflectance indices; WI, water index.

$\mathrm{S}$ ELECTION OF ADVANCED breeding materials for grain yield is a labor-intensive procedure and sometimes produces inaccurate results due to the complex genetic behavior of yield (Ball and Konzak, 1993). Grain yield is influenced directly and indirectly by a number of factors, such as morphology, physiology, and especially environmental conditions. Grain yield in wheat (Triticum aestivum L.) has low heritability and shows high genotype-environment interaction, and hence, selection becomes more difficult in a given environment (Jackson et al., 1996). Selection for grain yield by measuring yield itself is a classical approach, whereas selection for grain yield by considering indirect traits is an analytical approach (Richards, 1982). A good understanding of the factors responsible for growth and development is required to

Published in Crop Sci. 47:1416-1425 (2007)

doi: 10.2135/cropsci2006.08.0546

(C) Crop Science Society of America

677 S. Segoe Rd., Madison, WI 53711 USA

All rights reserved. No part of this periodical may be reproduced or transmitted in any form or by any means, electronic or mechanical, including photocopying, recording, or any information storage and retrieval system, without permission in writing from the publisher. Permission for printing and for reprinting the material contained herein has been obtained by the publisher. 
identify an indirect selection tool for improving grain yield in wheat (Richards, 1982).

Reynolds et al. (2001) emphasized the potential of using different morphophysiological selection criteria to complement empirical selection for grain yield, which potentially can make the selection process more efficient. So far, the use of this strategy is not well established in a large-scale breeding program due to the lack of knowledge about the indirect traits (Richards, 1996). Moreover, no comprehensive breeding and genetics studies have been reported about the usefulness of secondary traits for obtaining greater genetic gain for grain yield. However, there are reports that stomatal conductance, $\mathrm{C}_{13}$ isotope discrimination of grains, and canopy temperature depression can complement empirical selection for grain yield in different wheat growing areas (Reynolds et al., 1999). Canopy spectral reflectance has also recently been reported to be useful for predicting grain yield in wheat (Aparicio et al., 2000; Araus et al., 2001; Royo et al., 2003; Babar et al., 2006a).

The concept behind canopy spectral reflectance is that specific plant traits are associated with absorption of specific wavelengths of the light spectrum and, thus, show a characteristic reflectance pattern at a certain wavelength of the light spectrum (Reynolds et al., 1999). For example, chlorophylls, xanthophylls, and carotenoids strongly absorb light in the visible wavelengths and, thus, reflect only a smaller proportion of the visible wavelengths. The near-infrared portion of the light spectrum is not absorbed by these pigments, and hence, a significant portion of the near-infrared light is reflected from the canopy. The reflection pattern of the near-infrared wavelengths is governed by the structural behavior of the plant tissues (Peñuelas and Filella, 1998). Measurements of canopy spectral reflectance can provide useful information about green biomass, photosynthesis, relative water content, nutrient deficiencies, and environmental stresses (Araus et al., 2001; Reynolds et al., 2001).

Estimation of different morphophysiological properties of crop plants can be done by using spectral reflectance indices (SRI), which are based on mathematical equations between different wavelengths, such as sums, ratios, or differences (Araus et al., 2001). Among the indices, normalized difference vegetation index (NDVI) and simple ratio (SR) are the two most widely used SRI that have been reported to assess green biomass, leaf area index, and fraction of absorbed photosynthetically active radiation (Wiegand and Richardson, 1990; Baret and Guyot, 1991; Price and Bausch, 1995). The estimation of leaf area duration, an indicator of stress tolerance and absorbed photosynthetically active radiation, has been used to predict grain yield with periodic measurements of canopy spectral reflectance (Wiegand and Richardson, 1990). Prediction of early biomass in wheat was also reported by Elliott and Regan (1993). The water index (WI), developed by using the minor water absorption band $(970 \mathrm{~nm})$, has been demonstrated to approximate relative water content and other traits related to water content of the canopy (Peñuelas et al., 1993, 1997). The normalized difference vegetation index has been reported to predict grain yield in soybean (Glycine max L.) (Ma et al., 2001), in winter wheat (Raun et al., 2001), and in durum wheat (Triticum turgidum L.) (Aparicio et al., 2000). Serrano et al. (2000) reported that simple ratio can reliably predict winter wheat grain yield under nitrogen stresses. Babar et al. (2006a) reported the efficiency of the near-infrared indices in estimating spring wheat (Triticum aestivum L.) grain yield under northwestern Mexico conditions. The published literature is not decisive about the value of the SRI as indirect selection criteria for grain yield improvement in winter wheat in the Great Plains.

The efficiency of an indirect selection criterion compared to direct selection depends on the heritability of the indirect trait along with the genetic correlation between the direct and indirect traits, considering that equal selection intensities for both traits were practiced (Falconer, 1989). Information from SRI in terms of these two features is not available to ascertain the efficiency of using SRI as indirect selection tools for improving grain yield in winter wheat. Indirect selection has been shown to be more efficient, less efficient, or equally efficient compared to direct selection when different input levels were considered and selection was practiced to improve a trait in one environment by selecting the trait in another environment (Atlin and Frey, 1989; Calhoun et al., 1994; Sinebo et al., 2002). Most of the selection efficiency studies involved creating two diverse environments and selecting a trait in one environment that could be equally effective in another environment. The selection based on some combination of morphological traits has been reported to be equally effective as selection for dry matter directly in maize (Zea mays L.) (Gallais, 1984). One important consideration for an indirect trait relevant to a breeding program is that the heritability of the indirect traits and the genetic correlations between the direct and indirect traits should be measured in genetic populations closely representing the area where the improvement is being targeted. A comprehensive study is thus required in the Great Plains of the USA to determine the usefulness of the SRI for improvement of grain yield by using winter wheat developed in this region.

Therefore, the objectives of the study were to (i) estimate genetic correlations between the SRI and grain yield, (ii) estimate the heritability of the SRI, (iii) estimate the selection response of SRI and correlated selection response of grain yield through SRI, and (iv) estimate relative selection efficiency of the SRI for grain yield.

\section{MATERIALS AND METHODS}

The experiments were conducted at Oklahoma State University research farms at Stillwater and at Lake Carl Blackwell, 
$25 \mathrm{~km}$ west of Stillwater, Oklahoma, during the wheat growing seasons of 2003-2004 and 2004-2005. These sites have soil types of silty clay loam to fine sandy loam with an average $\mathrm{pH}$ of 6 to 7 (Stillwater: Kirkland silt loam [fine, mixed, thermic Udertic Paleustolls], pH 6.2-6.5; Lake Carl Blackwell: Pulaski fine sandy loam [coarse-loamy, mixed, nonacid, thermic Typic Ustifluvent], $\mathrm{pH}$ 6.7-6.9). The experiments were conducted under rain-fed conditions, with a seeding rate of $70 \mathrm{~kg} \mathrm{ha}^{-1}$. At both sites, $90 \mathrm{~kg} \mathrm{ha}^{-1}$ nitrogen was applied before planting. To control foliar diseases, Folicur 3.6F (38.7\% tebuconazole; Bayer CropScience, NC) was applied twice (late tillering and booting stage) and Cygon 2E (23\% dimethoate; Southern Agricultural Insecticides, Inc., FL) was applied once at the booting stage to control aphids.

\section{Plant Materials}

The plant materials consisted of three groups of winter wheat genotypes developed by different wheat breeding programs of the southern and central Great Plains. The first experiment (Exp-1) was composed of 25 commercial winter wheat cultivars and was planted at Stillwater and Lake Carl Blackwell in the 2003-2004 and 2004-2005 cropping seasons, respectively. The second experiment (Exp-2), designated as Population 1, contained $25 \mathrm{~F}_{4: 6}$ and $\mathrm{F}_{4: 7}$ recombinant inbred lines from the cross KS920709-B-5-2-2/Stanof, and was planted at Stillwater in 2003-2004 $\left(\mathrm{F}_{6}\right)$ and at Lake Carl Blackwell $\left(\mathrm{F}_{7}\right)$ in 2004-2005. The third experiment (Exp-3), designated as Population 2, consisted of $25 \mathrm{~F}_{4: 6}$ and $\mathrm{F}_{4: 7}$ recombinant inbred lines from the cross Longhorn/98IWS26 and was planted at Lake Carl Blackwell in both years $\left(\mathrm{F}_{6}\right.$ in $2003-2004$ and $\mathrm{F}_{7}$ in 2004-2005). All three experiments were established in a $5 \times 5$ alpha lattice design with two replications. Individual plot size was $3.0 \mathrm{~m} \times 1.2 \mathrm{~m}$ with $18-\mathrm{cm}$ spacing between the rows with 7 rows per plot. Grain yield from each plot was determined by mechanical harvesting of the whole plot.

\section{Reflectance Measurements}

Canopy spectral reflectance measurements were performed with a field spectroradiometer (FieldSpec UV/VNIR, Analytical Spectral Device, Boulder, CO). The radiometer has the capability of collecting the reflectance from 350 to $1050 \mathrm{~nm}$ of the light spectrum. Five hundred and twelve continuous data points from each reading were obtained with an interval of $1.4 \mathrm{~nm}$ between each reading. Cloud-free days were chosen to measure the reflectance, and data were taken in the middle of the day. The optical fiber of the sensor was placed $50 \mathrm{~cm}$ above the canopy with $25^{\circ}$ field of view. The incoming reflectance was calibrated against the reflectance from a white reflectance plate coated with $\mathrm{BaSO}_{4}$. Reflectance measurements were taken from four random places within each plot, and the mean of the four readings was used to estimate reflectance indices. Reflectance measurements were taken at booting (Zadoks stage 45), heading (Zadoks stage 59), and grain-filling (Zadoks stage 75) stages in all three experiments in both years (Zadoks et al., 1974).

Spectral reflectance indices were calculated as follows. Vegetation-based indices that are related to canopy photosynthetic area are

Red normalized difference vegetation index $(\mathrm{RNDVI})=$

$$
\left(\mathrm{R}_{780}-\mathrm{R}_{670}\right) /\left(\mathrm{R}_{780}+\mathrm{R}_{670}\right) \text {, Raun et al. (2001) }
$$

Green normalized difference vegetation index $($ GNDVI $)=$ $\left(\mathrm{R}_{780}-\mathrm{R}_{550}\right) /\left(\mathrm{R}_{780}+\mathrm{R}_{550}\right)$, Aparicio et al. (2000)

Simple ratio $(\mathrm{SR})=\left(\mathrm{R}_{900} / \mathrm{R}_{680}\right)$, Gitelson et al. (1996)

Water-based indices that indicate the canopy water status are

Water index $(\mathrm{WI})=\left(\mathrm{R}_{970} / \mathrm{R}_{900}\right)$, Peñuelas et al. (1993)

Normalized water index 1

$(\mathrm{NWI}-1)=\left(\mathrm{R}_{970}-\mathrm{R}_{900}\right) /\left(\mathrm{R}_{970}+\mathrm{R}_{900}\right)$, Babar et al. (2006a)

Normalized water index 2

$(\mathrm{NWI}-2)=\left(\mathrm{R}_{970}-\mathrm{R}_{850}\right) /\left(\mathrm{R}_{970}+\mathrm{R}_{850}\right)$, Babar et al. (2006a)

Initially, 200 indices were developed based on combinations of visible and near-infrared wavelengths in ratio and normalized forms. Based on the overall performance of the indices in predicting grain yield variations for different experimental genotypes, two new normalized water indices were selected as follows:

Normalized water index 3

$(\mathrm{NWI}-3)=\left(\mathrm{R}_{970}-\mathrm{R}_{920}\right) /\left(\mathrm{R}_{970}+\mathrm{R}_{920}\right)$

Normalized water index 4

$(\mathrm{NWI}-4)=\left(\mathrm{R}_{970}-\mathrm{R}_{880}\right) /\left(\mathrm{R}_{970}+\mathrm{R}_{880}\right)$

$\mathrm{R}$ and the subscript indicate the light reflectance at the specific wavelengths (in $\mathrm{nm}$ ).

\section{Statistical Analysis}

SAS PROC MIXED (SAS Institute, 2001) was used for alpha lattice analysis for grain yield and spectral reflectance indices. Phenotypic and genetic correlation coefficients were estimated to reveal the association between the indices and grain yield. The genetic correlation coefficients between the SRI and grain yield were calculated by the formula (Falconer, 1989)

$$
r_{\mathrm{g}}=\left(\operatorname{Cov}_{\mathrm{X} 1 \mathrm{X} 2}\right) / \sqrt{ }\left(\operatorname{Var}_{\mathrm{X} 1} \times \operatorname{Var}_{\mathrm{X} 2}\right)
$$

where $\operatorname{Cov}_{\mathrm{X} 1 \mathrm{x} 2}$ is the genetic covariance between the two variables, and $\operatorname{Var}_{\mathrm{X} 1}$ and $\operatorname{Var}_{\mathrm{X} 2}$ are the genetic variances of the variables, estimated across growth stages. Broad-sense heritabilities $\left(h^{2}\right)$ were calculated on a plot mean basis as defined by Falconer (1989). Broad-sense heritability is the proportion of the phenotypic variance to the total genetic variance and was estimated as

$$
h^{2}=\sigma_{\mathrm{g}}^{2} /\left(\sigma_{\mathrm{g}}^{2}+\sigma_{\mathrm{e}}^{2}\right)
$$

where, $\sigma^{2}$ is the genotypic variance and $\sigma^{2}$ is the error variance. Response to selection $(R)$ of the SRI and grain yield and correlated response $(C R)$ for grain yield by using SRI were calculated according to Falconer (1989) as

$$
R=h_{\mathrm{x}} \sigma_{\mathrm{x}}
$$

where $h_{\mathrm{x}}$ is the square root of heritability and $\sigma_{\mathrm{x}}$ is the genotypic standard deviation,

$$
C R=h_{\mathrm{x}} r_{\mathrm{g}} \sigma_{\mathrm{y}}
$$

where $h_{\mathrm{x}}$ is the square root of heritability of trait $\mathrm{x}$ (SRI), $r_{\mathrm{g}}$ is the genetic correlation between the trait $\mathrm{x}$ (SRI) and y (yield), and $\sigma_{\mathrm{y}}$ is the genotypic standard deviation of trait y (yield), assuming the selection intensity is equal in different generations. The relative selection efficiency was calculated as the ratio of $C R$ of grain yield for a specific SRI and $R$ of grain yield (Falconer, 1989).

Data from the different SRI were analyzed to obtain principal components by principal component analysis. Principal component analysis provides a better way to classify the contribution of different indices rather than each index individually (Filella et al., 1995). The principal component analysis was done for each experiment with mean grain yield over $2 \mathrm{yr}$ and mean index values over different growth stages and years. 
Table 1. Mean $( \pm S E)$ of spectral reflectance indices at three growth stages for three experiments, estimated based on combined years.

\begin{tabular}{|c|c|c|c|c|c|c|c|c|c|}
\hline \multirow{2}{*}{ Exp. } & \multirow{2}{*}{$\begin{array}{l}\text { Growth } \\
\text { stages }\end{array}$} & \multicolumn{8}{|c|}{ Spectral reflectance indices ${ }^{\dagger}$} \\
\hline & & RNDVI & GNDVI & SR & WI & NWI-1 & NWI-2 & NWI-3 & NWI-4 \\
\hline \multirow{3}{*}{ Exp-1 } & Booting & $0.899 \pm 0.02$ & $0.807 \pm 0.02^{\star *}$ & $22.2 \pm 2.6^{\star \star}$ & $0.846 \pm 0.013^{\star *}$ & $-0.083 \pm 0.008^{\star \star}$ & $-0.08 \pm 0.009^{\star *}$ & $-0.082 \pm 0.007^{\star *}$ & $-0.089 \pm 0.009^{\star *}$ \\
\hline & Heading & $0.862 \pm 0.02^{\star \star}$ & $0.764 \pm 0.03^{\star \star}$ & $15.5 \pm 1.4^{\star \star}$ & $0.864 \pm 0.01^{\star \star}$ & $-0.073 \pm 0.006^{\star \star}$ & $-0.064 \pm 0.006^{\star \star}$ & $-0.073 \pm 0.005^{\star *}$ & $-0.073 \pm 0.006^{\star \star}$ \\
\hline & Grain-filling & $0.756 \pm 0.04^{\star}$ & $0.692 \pm 0.03^{\star \star}$ & $8.5 \pm 1.6^{\star \star}$ & $0.892 \pm 0.013^{\star \star}$ & $-0.057 \pm 0.007^{\star \star}$ & $-0.045 \pm 0.009^{\star \star}$ & $-0.059 \pm 0.006$ ** & $-0.056 \pm 0.008^{\star \star}$ \\
\hline \multirow{3}{*}{ Exp-2 } & Booting & $0.912 \pm 0.01$ & $0.823 \pm 0.01$ & $27.6 \pm 2.7^{\star}$ & $0.836 \pm 0.009$ & $-0.090 \pm 0.005$ & $-0.087 \pm 0.007$ & $-0.088 \pm 0.005^{\star}$ & $-0.091 \pm 0.006$ \\
\hline & Heading & $0.908 \pm 0.01^{*}$ & $0.807 \pm 0.01^{\star \star}$ & $23.2 \pm 2.3^{\star \star}$ & $0.834 \pm 0.012^{*}$ & $-0.091 \pm 0.007^{*}$ & $-0.085 \pm 0.009$ & $-0.090 \pm 0.007^{*}$ & $-0.094 \pm 0.008^{*}$ \\
\hline & Grain-filling & $0.607 \pm 0.03^{\star \star}$ & $0.602 \pm 0.02^{\star \star}$ & $5.1 \pm 0.72^{\star \star}$ & $0.934 \pm 0.011^{\star \star}$ & $-0.034 \pm 0.006^{\star \star}$ & $-0.013 \pm 0.008$ & $-0.039 \pm 0.005^{\star \star}$ & $-0.031 \pm 0.007^{\star \star}$ \\
\hline \multirow{3}{*}{ Exp-3 } & Booting & $0.878 \pm 0.02$ & $0.746 \pm 0.02^{\star \star}$ & $17.2 \pm 2.9^{\star}$ & $0.886 \pm 0.015^{\star \star}$ & $-0.061 \pm 0.008^{\star \star}$ & $-0.058 \pm 0.009^{\star \star}$ & $-0.061 \pm 0.007^{\star *}$ & $-0.062 \pm 0.009^{\star *}$ \\
\hline & Heading & $0.857 \pm 0.02^{\star *}$ & $0.743 \pm 0.02^{* *}$ & $14.1 \pm 1.9^{\star \star}$ & $0.861 \pm 0.012^{* *}$ & $-0.075 \pm 0.007^{\star \star}$ & $-0.067 \pm 0.007^{\star *}$ & $-0.074 \pm 0.006^{\star \star}$ & $-0.075 \pm 0.007^{\star \star}$ \\
\hline & Grain-filling & $0.743 \pm 0.04^{\star \star}$ & $0.677 \pm 0.02^{\star \star}$ & $7.3 \pm 1.3^{\star *}$ & $0.892 \pm 0.014^{\star \star}$ & $-0.057 \pm 0.008^{\star \star}$ & $-0.043 \pm 0.01^{\star \star}$ & $-0.060 \pm 0.007$ & $-0.057 \pm 0.009^{\star *}$ \\
\hline
\end{tabular}

*Significant at the 0.05 probability level.

**Significant at the 0.01 probability level.

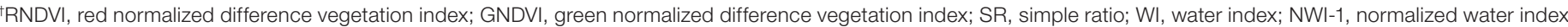
1; NWI-2, normalized water index 2; NWI-3, normalized water index 3; NWI-4, normalized water index 4.

\section{Selection of Genotypes}

For selection of genotypes, we first ranked the genotypes based on grain yield and selected the top 25\% highest-yielding genotypes. Then, we ranked the genotypes based on the SRI values and selected the top $25 \%$ of the genotypes. The ranking of the genotypes was done based on mean index values over three growth stages. Mean yield and mean predicted yield of the top 25\% highest-yielding genotypes using linear regression between grain yield and SRI were compared and percent yield differences were calculated to determine the effectiveness of the SRI in selecting higher-yielding genotypes.

\section{RESULTS AND DISCUSSION Genotypes and Growth Stages}

Grain yield was significantly different $(p<0.05)$ among genotypes in all three experiments in both years and across years. Mean grain yield of the cultivars in Exp-1 was 5026 $\mathrm{kg} \mathrm{ha}^{-1}$ in year 2003-2004, $3571 \mathrm{~kg} \mathrm{ha}^{-1}$ in year 20042005, and $4299 \mathrm{~kg} \mathrm{ha}^{-1}$ when data were combined for 2 yr. In Exp-2 (Population 1), mean grain yield was $4608 \mathrm{~kg}$ $\mathrm{ha}^{-1}, 3177 \mathrm{~kg} \mathrm{ha}^{-1}$, and $3899 \mathrm{~kg} \mathrm{ha}^{-1}$ for year 2003-2004, 2004-2005, and across years. Mean grain yield in Exp-3 (Population 2) was $4301 \mathrm{~kg} \mathrm{ha}^{-1}, 2521 \mathrm{~kg} \mathrm{ha}^{-1}$, and 3411 $\mathrm{kg} \mathrm{ha}^{-1}$ in year 2003-2004, 2004-2005, and across years, respectively. The across years yield ranged from $2921 \mathrm{~kg}$ $\mathrm{ha}^{-1}$ to $5001 \mathrm{~kg} \mathrm{ha}^{-1}$ in Exp-1, $2785 \mathrm{~kg} \mathrm{ha}^{-1}$ to $4831 \mathrm{~kg} \mathrm{ha}^{-1}$ in Exp-2, and $2842 \mathrm{~kg} \mathrm{ha}^{-1}$ to $4132 \mathrm{~kg} \mathrm{ha}^{-1}$ in Exp-3.

The means $( \pm \mathrm{SE})$ of the SRI at three growth stages (booting, heading, and grain-filling) for three experiments are presented in Table 1 . All indices showed significant variation $(p<0.05)$ among genotypes in the different experiments at the heading and grain-filling stages, with some nonsignificant variation at the booting stage. These results suggest that the heading and grain-filling stages are the best growth stages for measuring the SRI. Similar observations were reported in irrigated spring wheat (Babar et al., 2006a), in durum wheat (Aparicio et al., 2000; Royo et al., 2003), and in winter wheat (Prasad et al., 2007). The estimates of the vegetation-based indices (RNDVI, GNDVI, and SR) showed a decreasing trend from the booting to grain-filling stage (Table 1). The highest estimates of these indices at the booting stage were due to the highest amount of green leaf area and the highest leaf area index occurring at this stage. The decrease in green tissue with the progression of growth stages resulted in a decrease in the index values in subsequent growth stages. Since these three indices were developed by using the visible and near-infrared wavelengths (see materials and methods for index calculation), they follow the changes in the loss of green mass. Knipling (1970) reported that reflectance in the visible wavelengths increases as green tissues start to collapse and near-infrared reflectance decreases. The near-infrared-based indices (WI and NWI) always had the highest value at the grain-filling stage, and, in most cases, they showed the lowest values at the heading stage (Table 1). These indices contain the 970$\mathrm{nm}$ minor water absorption band (see Materials and Methods for index calculation). The most important property of this $970-\mathrm{nm}$ wavelength has been reported to approximate the water content of the canopy (Peñuelas et al., 1997). The highest values at the grain-filling stage indicate the lowest amount of canopy water content at grain-filling. Conversely, the lowest values for the water-based indices at the heading stage indicate the highest water content in the canopy during heading. This behavior of the water-based indices was also reported in irrigated spring wheat (Babar et al., 2006a) and in winter wheat (Prasad et al., 2007).

\section{Correlation between SRI and Grain Yield}

Significant phenotypic correlations between the SRI and grain yield were observed in both years and across years, with a few exceptions (Table 2). The vegetation-based indices (RNDVI, GNDVI, and SR) always showed positive correlation coefficients. Similar positive correlations have been reported in rain-fed durum wheat environments 
Table 2. Phenotypic correlation between grain yield and different spectral reflectance indices in 2 yr and across years in Exp-1.

\begin{tabular}{|c|c|c|c|c|c|c|c|c|c|}
\hline \multirow{2}{*}{ Year } & \multirow{2}{*}{ Growth stages } & \multicolumn{8}{|c|}{ Spectral reflectance indices ${ }^{\dagger}$} \\
\hline & & RNDVI & GNDVI & SR & WI & NWI-1 & NWI-2 & NWI-3 & NWI-4 \\
\hline \multirow[t]{5}{*}{ 2003-2004 } & Booting & $0.55^{\star \star}$ & $0.59^{\star \star}$ & $0.58^{\star \star}$ & $-0.55^{\star \star}$ & $-0.56^{\star \star}$ & $-0.53^{\star \star}$ & $-0.54^{\star \star}$ & $-0.54^{\star \star}$ \\
\hline & Heading & $0.62^{* *}$ & $0.59^{\star \star}$ & $0.56^{\star \star}$ & $-0.69^{\star *}$ & $-0.69^{\star *}$ & $-0.72^{\star \star}$ & $-0.66^{\star \star}$ & $-0.71^{\star \star}$ \\
\hline & Grain-filling & $0.67^{\star \star}$ & $0.64^{\star *}$ & $0.63^{\star *}$ & $-0.74^{\star \star}$ & $-0.74^{\star \star}$ & $-0.70^{\star \star}$ & $-0.75^{\star \star}$ & $-0.72^{* \star}$ \\
\hline & Average ${ }^{\ddagger}$ & $0.71^{\star \star}$ & $0.69^{\star *}$ & $0.71^{\star \star}$ & $-0.76^{\star \star}$ & $-0.76^{\star \star}$ & $-0.73^{\star \star}$ & $-0.76^{\star \star}$ & $-0.75^{\star \star}$ \\
\hline & Average ${ }^{\S}$ & $0.70^{\star *}$ & $0.65^{\star \star}$ & $0.63^{\star \star}$ & $-0.73^{\star \star}$ & $-0.73^{\star \star}$ & $-0.73^{\star \star}$ & $-0.73^{\star \star}$ & $-0.73^{\star *}$ \\
\hline \multirow[t]{5}{*}{ 2004-2005 } & Booting & $0.69^{\star *}$ & $0.52^{\star \star}$ & $0.64^{\star *}$ & $-0.81^{\star \star}$ & $-0.81^{\star \star}$ & $-0.77^{\star *}$ & $-0.80^{\star *}$ & $-0.78^{* *}$ \\
\hline & Heading & $0.43^{*}$ & 0.13 & $0.43^{*}$ & $-0.66^{\star \star}$ & $-0.66^{\star \star}$ & $-0.70^{\star *}$ & $-0.63^{\star \star}$ & $-0.69^{\star *}$ \\
\hline & Grain-filling & 0.30 & -0.02 & 0.30 & $-0.69^{\star \star}$ & $-0.69^{\star \star}$ & $-0.58^{\star \star}$ & $-0.72^{\star \star}$ & $-0.65^{\star \star}$ \\
\hline & Average $^{\ddagger}$ & $0.52^{\star \star}$ & 0.21 & $0.59^{\star *}$ & $-0.83^{\star \star}$ & $-0.83^{\star \star}$ & $-0.82^{\star \star}$ & $-0.83^{\star \star}$ & $-0.84^{\star \star}$ \\
\hline & Average & 0.38 & 0.06 & $0.41^{*}$ & $-0.75^{\star \star}$ & $-0.75^{\star \star}$ & $-0.73^{\star \star}$ & $-0.75^{\star \star}$ & $-0.77^{\star \star}$ \\
\hline \multirow[t]{5}{*}{ Across years } & Booting & $0.68^{\star *}$ & $0.58^{\star \star}$ & $0.64^{\star *}$ & $-0.66^{\star \star}$ & $-0.66^{\star \star}$ & $-0.60^{\star \star}$ & $-0.65^{\star \star}$ & $-0.62^{\star \star}$ \\
\hline & Heading & $0.58^{\star *}$ & 0.36 & $0.54^{\star *}$ & $-0.66^{\star \star}$ & $-0.66^{\star \star}$ & $-0.68^{\star \star}$ & $-0.63^{\star *}$ & $-0.68^{\star \star}$ \\
\hline & Grain-filling & $0.56^{\star *}$ & 0.35 & $0.50^{\star}$ & $-0.71^{\star *}$ & $-0.70^{\star \star}$ & $-0.65^{\star \star}$ & $-0.72^{\star *}$ & $-0.68^{* *}$ \\
\hline & Average $^{\ddagger}$ & $0.69^{* *}$ & $0.47^{\star \star}$ & $0.68^{\star *}$ & $-0.78^{\star \star}$ & $-0.78^{\star \star}$ & $-0.74^{\star \star}$ & $-0.78^{\star *}$ & $-0.77^{\star \star}$ \\
\hline & Average $^{\S}$ & $0.61^{\star \star}$ & 0.38 & $0.56^{\star \star}$ & $-0.72^{\star \star}$ & $-0.72^{\star \star}$ & $-0.70^{\star \star}$ & $-0.71^{\star \star}$ & $-0.72^{\star \star}$ \\
\hline
\end{tabular}

${ }^{*}$ Significant at the 0.05 probability level.

${ }^{* *}$ Significant at the 0.01 probability level.

${ }^{+}$RNDVI, red normalized difference vegetation index; GNDVI, green normalized difference vegetation index; SR, simple ratio; WI, water index; NWI-1, normalized water index 1; NWI-2, normalized water index 2; NWI-3, normalized water index 3; NWI-4, normalized water index 4.

${ }^{\ddagger}$ Correlation coefficients were estimated based on average index value from booting, heading, and grain-filling stages.

${ }^{s}$ Correlation coefficients were estimated based on average index value from heading and grain-filling stages.

(Aparicio et al., 2000; Royo et al., 2003). In most cases, RNDVI, GNDVI, and SR showed higher phenotypic correlations when data were combined from the different growth stages, especially combining the three growth stages (Table 2).

The indices based on the minor water absorption band (WI and NWI) always showed significant and higher phenotypic correlation coefficients compared to the vegetationbased indices (Table 2). The correlation became stronger when the relationship was assessed by combining the three growth stages (Table 2). Combining two growth stages (heading and grain-filling) also produced similar trends, but they were lower than the three growth stage combinations. The better association between the SRI and grain yield based on the combined growth stage information can be hypothesized as being a better picture of overall plant health during the crop growing period assessed by the SRI. The water-based indices estimate water content of the canopy, and the higher associations between these indices and grain yield indicate that canopy water content plays a vital role in the productivity of a given genotype under rain-fed conditions. Using combined reflectance information from different growth stages for predicting grain yield was also reported for irrigated spring wheat (Babar et al., 2006a) and winter wheat (Prasad et al., 2007). Although three readings always resulted in higher associations compared to one or two readings, from a practical point of view, we recommend taking reflectance measurements at heading and at grain-filling and combining the information from the two readings. We estimated the genetic correlation between the SRI and grain yield in two populations (Exp-2 and Exp-3) of recombinant inbred lines (Table 3). All indices showed significant genetic correlation with grain yield in both years and across years for both populations. The water-based indices showed a higher association at the genetic level than the vegetation-based indices, suggesting that canopy water content is more powerful in predicting grain yield. Higher genetic correlations between the water-based indices and grain yield in randomly derived recombinant lines established the genetic basis for the relationship between grain yield and SRI.

The percent of the variation for grain yield that is explained by the SRI in the two populations (Exp-2 and Exp-3) is presented in Table 4. The coefficients were calculated based on individual growth stages, and two combinations of growth stages (combining booting, heading, and grain-filling, and combining heading and grain-filling). The water-based indices showed better predictability for grain yield variability compared to the vegetation-based indices (RNDVI, GNDVI, and SR) (Table 4). The combination of growth stages SRI information was more predictive than individual growth stages. We suggest measuring SRI multiple times, at least once at heading and again at grain-filling, and utilizing the mean of the two readings. The mean grain yield for $2 \mathrm{yr}$ and mean index value of NWI-3 for the three growth stages and across years for Population 1 are plotted in Fig. 1. The NWI-3 (and the other water-based indices) did not saturate at higher yield levels (around 5.0 tons ha ${ }^{-1}$ ) among the genotypes under study. This means that breeders can effectively use this index for discriminating genotypes among breeding materials having grain yield up to 5.0 tons 
$\mathrm{ha}^{-1}$, which would be considered as a high yield under Great Plains rain-fed environments.

The water-based indices were basically indistinguishable from each other. It was reported earlier that normalizing can improve the relationship over a ratio index (Tucker, 1979). Babar et al. (2006a, 2006b) reported that the normalized index did not produce significantly better results over the ratio index for predicting yield and biomass in spring wheat. This is also evident in our studies. We used a multivariate approach to look at all the indices together, instead of each index separately. Filella et al. (1995) suggested that the multivariate approach can classify the variables according to their relationship with each other and can identify unique variables that are a true representation of the function of the variables. Axis 1 measures the normalized water indices in a positive direction. Yield and the vegetation-based indices (RNDVI, GNDVI, and SR) measure in a negative direction in all three experiments (Fig. 2). The relationship between the different indices can be eas-
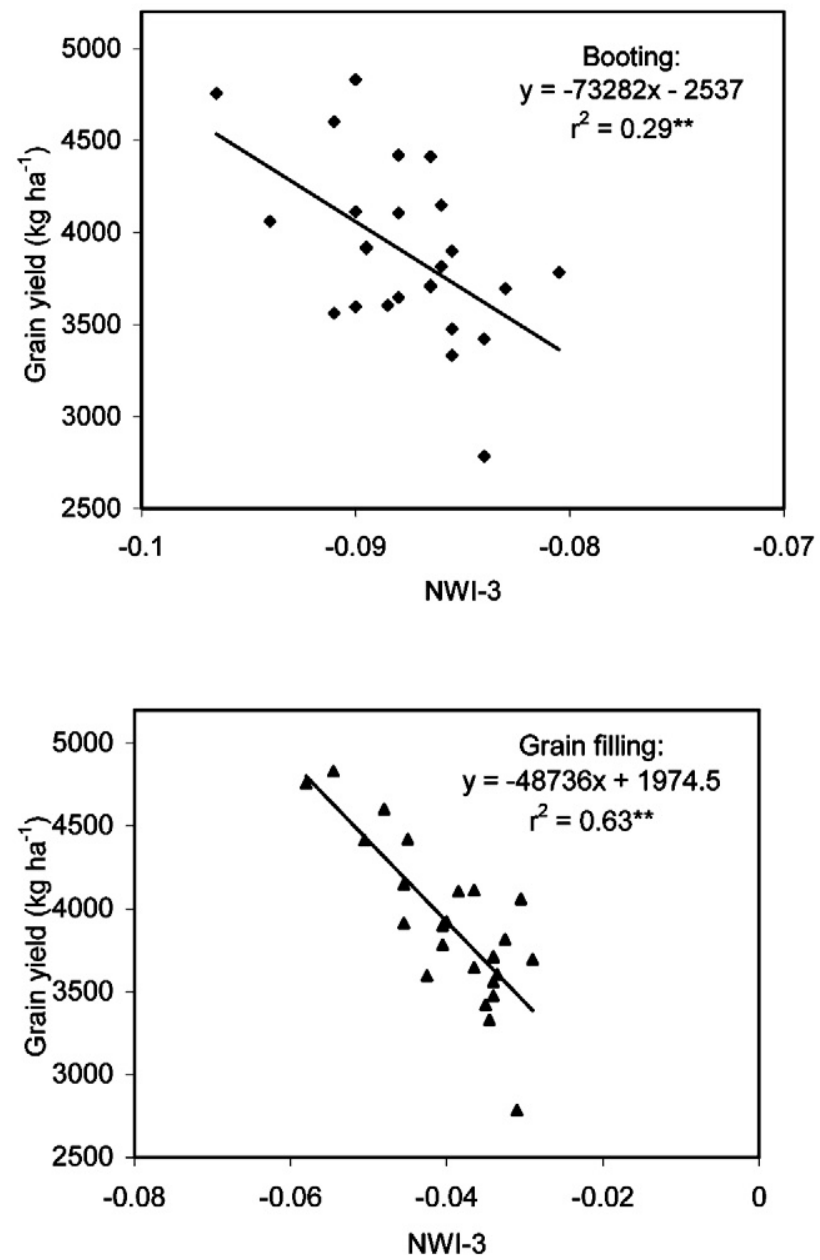

Figure 1. Linear relationship between grain yield and normalized water index 3 (NWI-3) at three growth stages and averaged over growth stages for Population 1. ** Significant at the 0.01 probability level.

ily visualized from the plots. All the normalized water indices grouped together with a very strong negative correlation with grain yield (Fig. 2). We conclude that all the normalized water indices are measuring similar parameters within the crop canopy. Similarly, RNDVI, GNDVI, and SR are measuring related parameters, as
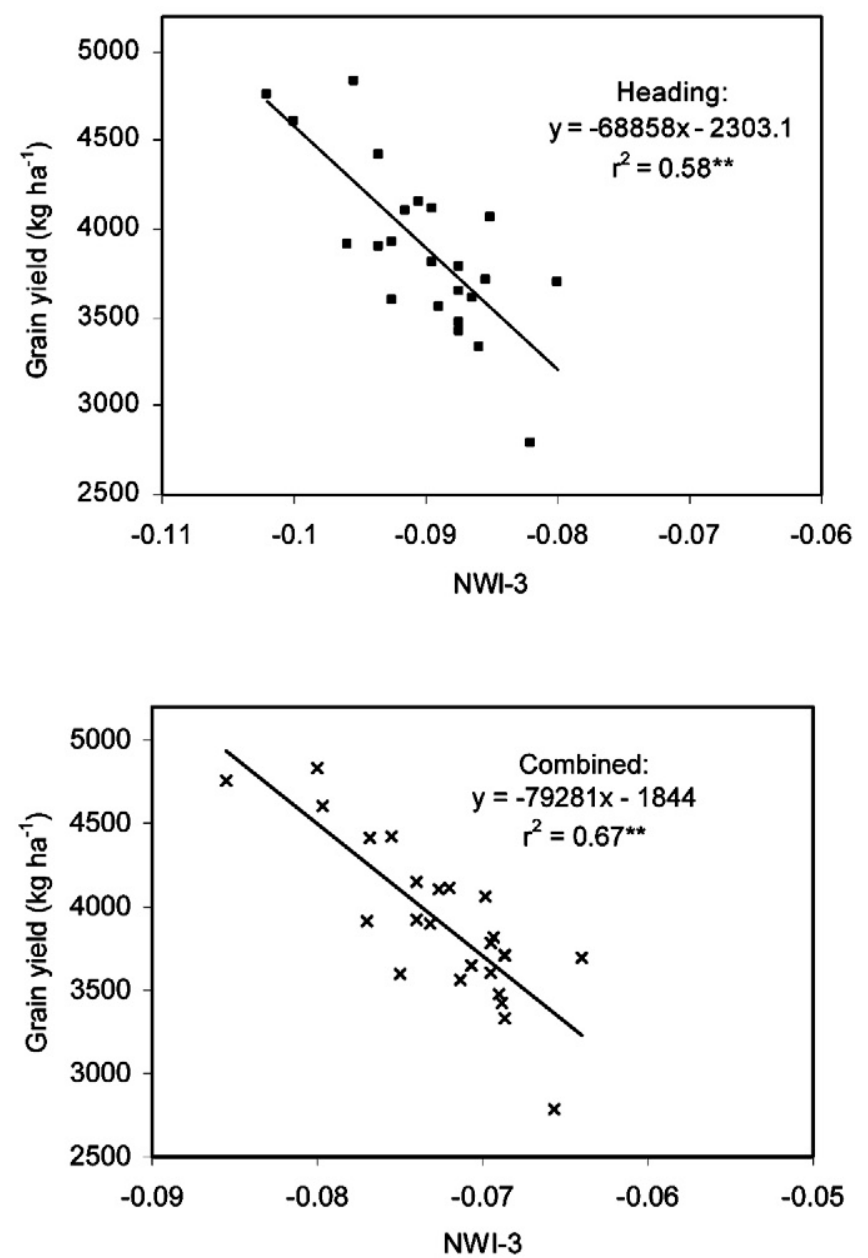
they were grouped together. The principal component analysis also revealed that the water-based indices have a stronger relationship with grain yield compared to the vegetation-based indices (Fig. 2).

\section{Heritability}

Broad-sense heritabilities for grain yield ranged from 0.44 to 0.63 in two populations in two different years and across years (Table 5). The heritability of the vegetation indices (RNDVI, GNDVI, and SR) ranged from 0.46 to 0.74 (Table 5). The water-based indices showed higher heritability compared to the veg-

Table 4. Coefficient of determination $\left(r^{2}\right)$ of different spectral reflectance indices for explaining grain yield variability in two recombinant inbred populations for two years.

\begin{tabular}{|c|c|c|c|c|c|c|c|c|c|}
\hline \multirow{2}{*}{ Experiment } & \multirow{2}{*}{$\begin{array}{l}\text { Growth } \\
\text { stages }\end{array}$} & \multicolumn{8}{|c|}{ Spectral reflectance indices ${ }^{\dagger}$} \\
\hline & & RNDVI & GNDVI & SR & WI & NWI-1 & NWI-2 & NWI-3 & NWI-4 \\
\hline \multicolumn{10}{|l|}{ Population 1} \\
\hline \multirow[t]{5}{*}{ Year 2003-2004 } & Booting & $0.18^{\star}$ & $0.24^{*}$ & $0.20^{\star}$ & $0.41^{\star \star}$ & $0.40^{* *}$ & $0.43^{\star *}$ & $0.40^{* *}$ & $0.40^{* *}$ \\
\hline & Heading & $0.30^{\star *}$ & $0.36^{\star \star}$ & $0.27^{\star \star}$ & $0.41^{* *}$ & $0.41^{* *}$ & $0.35^{\star \star}$ & $0.39^{* *}$ & $0.35^{\star \star}$ \\
\hline & Grain-filling & $0.20^{*}$ & $0.20^{*}$ & $0.28^{\star *}$ & $0.47^{\star *}$ & $0.46^{\star *}$ & $0.42^{\star *}$ & $0.47^{\star *}$ & $0.43^{\star \star}$ \\
\hline & Average $\neq$ & $0.24^{\star}$ & $0.34^{\star \star}$ & $0.40^{\star *}$ & $0.62^{* *}$ & $0.62^{\star *}$ & $0.56^{\star \star}$ & $0.65^{\star \star}$ & $0.58^{\star *}$ \\
\hline & Average $\S$ & $0.22^{*}$ & $0.28^{\star *}$ & $0.32^{\star \star}$ & $0.52^{\star *}$ & $0.52^{\star *}$ & $0.46^{\star *}$ & $0.53^{\star *}$ & $0.48^{\star *}$ \\
\hline \multirow[t]{5}{*}{ Year 2004-2005 } & Booting & 0.13 & $0.37^{\star *}$ & 0.12 & $0.16^{\star}$ & 0.15 & $0.16^{\star}$ & $0.17^{\star}$ & $0.18^{*}$ \\
\hline & Heading & $0.57^{\star \star}$ & $0.63^{\star \star}$ & $0.53^{\star *}$ & $0.66^{\star *}$ & $0.67^{\star \star}$ & $0.74^{\star \star}$ & $0.62^{\star \star}$ & $0.68^{\star \star}$ \\
\hline & Grain-filling & $0.57^{\star \star}$ & $0.64^{\star *}$ & $0.56^{\star \star}$ & $0.79^{\star *}$ & $0.79^{\star \star}$ & $0.72^{\star \star}$ & $0.80^{\star \star}$ & $0.76^{\star \star}$ \\
\hline & Average $^{\ddagger}$ & $0.61^{\star *}$ & $0.71^{\star \star}$ & $0.43^{\star \star}$ & $0.73^{\star \star}$ & $0.72^{\star \star}$ & $0.74^{\star \star}$ & $0.71^{\star *}$ & $0.73^{\star \star}$ \\
\hline & Average $^{\S}$ & $0.64^{\star *}$ & $0.73^{\star \star}$ & $0.61^{\star \star}$ & $0.77^{\star \star}$ & $0.77^{\star *}$ & $0.77^{\star *}$ & $0.75^{\star \star}$ & $0.77^{\star \star}$ \\
\hline \multicolumn{10}{|l|}{ Population 2} \\
\hline \multirow[t]{5}{*}{ Year 2003-2004 } & Booting & $0.45^{\star *}$ & $0.19^{\star}$ & $0.47^{\star *}$ & $0.46^{\star \star}$ & $0.46^{* *}$ & $0.49^{\star \star}$ & $0.43^{* *}$ & $0.47^{\star \star}$ \\
\hline & Heading & $0.34^{\star *}$ & $0.39^{\star \star}$ & $0.22^{*}$ & $0.51^{* *}$ & $0.50^{\star *}$ & $0.40^{* *}$ & $0.54^{\star \star}$ & $0.45^{\star \star}$ \\
\hline & Grain-filling & 0.13 & 0.14 & 0.13 & $0.32^{* *}$ & $0.31^{\star \star}$ & $0.17^{*}$ & $0.30^{* *}$ & $0.19^{*}$ \\
\hline & Average $\mathrm{e}^{\ddagger}$ & $0.37^{\star *}$ & $0.35^{\text {** }}$ & $0.45^{\star \star}$ & $0.63^{\star *}$ & $0.63^{* \star}$ & $0.53^{\star *}$ & $0.64^{* *}$ & $0.58^{\star *}$ \\
\hline & Average & $0.23^{\star}$ & $0.28^{\star \star}$ & $0.20^{\star}$ & $0.44^{\star *}$ & $0.43^{* *}$ & $0.31^{* *}$ & $0.44^{\star *}$ & $0.35^{\star \star}$ \\
\hline \multirow[t]{5}{*}{ Year 2004-2005 } & Booting & $0.39 * *$ & $0.20^{*}$ & $0.37^{\star \star}$ & $0.40^{* *}$ & $0.40^{* *}$ & $0.38^{* *}$ & $0.38^{\star *}$ & $0.38^{\star \star}$ \\
\hline & Heading & 0.39 ** & $0.23^{*}$ & $0.34^{* *}$ & $0.58^{* *}$ & $0.59^{* *}$ & $0.59^{* *}$ & $0.59^{* *}$ & $0.60^{* *}$ \\
\hline & Grain-filling & $0.28^{\star \star}$ & $0.24^{*}$ & $0.27^{\text {** }}$ & $0.39^{* *}$ & $0.40^{* *}$ & $0.29^{\star \star}$ & $0.39^{\star *}$ & $0.30^{\star *}$ \\
\hline & Average $^{\ddagger}$ & $0.40^{\star \star}$ & $0.27^{\star \star}$ & $0.40^{\star *}$ & $0.57^{\star \star}$ & $0.58^{* \star}$ & $0.51^{\star \star}$ & $0.58^{\star \star}$ & $0.52^{\star \star}$ \\
\hline & Average ${ }^{\S}$ & $0.34^{\star \star}$ & $0.26^{\star \star}$ & $0.34^{\star \star}$ & $0.52^{\star *}$ & $0.53^{* \star}$ & $0.43^{\star \star}$ & $0.53^{\star \star}$ & $0.45^{\star \star}$ \\
\hline
\end{tabular}

*Significant at the 0.05 probability level.

${ }^{* *}$ Significant at the 0.01 probability level.

${ }^{\dagger} R N D V I$, red normalized difference vegetation index; GNDVI, green normalized difference vegetation index; SR, simple ratio; WI, water index; NWI-1, normalized water index 1; NWI-2, normalized water index 2; NWI-3, normalized water index 3; NWI-4, normalized water index 4

‡Coefficients were estimated based on average index value from booting, heading, and grain-filling stages.

${ }^{\S}$ Coefficients were estimated based on average index value from heading and grain-filling stages. etation indices. The heritability calculated in this study is the proportion of phenotypic variance that is due to the genetic effect. These heritabilities indicate the repeatability of the indices at different times. Grain yield heritability was lower compared to the reflectance indices, indicating that grain yield is more environmentally influenced than the SRI. On the other hand, the waterbased indices showed a higher heritability than the vegetation-based indices, indicating that the water-based indices are more repeatable than the vegetationbased indices. High heritability of the water-based indices is suggestive of the scope for higher genetic gain in grain yield through selection.

\section{Selection Response, Correlated Response, and Relative Selection Efficiency}

The response to selection $(R)$ for SRI and grain yield, correlated response $(C R)$ for grain yield using SRI, and relative selection efficiency of the SRI for grain yield are presented in Table 6 . In general, the SRI showed higher selection response compared to grain yield (Table 6). Among the SRI, the waterbased indices had higher direct response compared to the vegetation-based indi-

Table 5. Broad-sense heritability ( \pm SE) for grain yield and spectral reflectance indices (average of booting, heading, and grainfilling stages) in two recombinant inbred populations for two years and across years.

\begin{tabular}{llcccccccc}
\hline \multirow{2}{*}{ Experiments } & Grain yield & \multicolumn{7}{c}{ Spectral reflectance indices $^{\dagger}$} \\
\cline { 3 - 9 } & & RNDVI & GNDVI & SR & WI & NWI-1 & NWI-2 & NWI-3 & NWI-4 \\
\hline Population 1 & & & & & & & \\
Year 2003-2004 & $0.45 \pm 0.02$ & $0.66 \pm 0.07$ & $0.64 \pm 0.05$ & $0.62 \pm 0.05$ & $0.62 \pm 0.07$ & $0.62 \pm 0.06$ & $0.69 \pm 0.04$ & $0.63 \pm 0.07$ & $0.66 \pm 0.05$ \\
Year 2004-2005 & $0.63 \pm 0.04$ & $0.74 \pm 0.05$ & $0.72 \pm 0.04$ & $0.58 \pm 0.05$ & $0.78 \pm 0.06$ & $0.78 \pm 0.05$ & $0.69 \pm 0.05$ & $0.78 \pm 0.08$ & $0.78 \pm 0.04$ \\
Combined & $0.58 \pm 0.03$ & $0.71 \pm 0.05$ & $0.71 \pm 0.04$ & $0.59 \pm 0.07$ & $0.77 \pm 0.07$ & $0.75 \pm 0.05$ & $0.78 \pm 0.05$ & $0.76 \pm 0.05$ & $0.76 \pm 0.06$ \\
Population 2 & & & & & & & & \\
Year 2003-2004 & $0.57 \pm 0.05$ & $0.50 \pm 0.05$ & $0.46 \pm 0.03$ & $0.49 \pm 0.04$ & $0.68 \pm 0.08$ & $0.64 \pm 0.05$ & $0.73 \pm 0.07$ & $0.69 \pm 0.04$ & $0.76 \pm 0.04$ \\
Year 2004-2005 & $0.54 \pm 0.03$ & $0.65 \pm 0.06$ & $0.59 \pm 0.02$ & $0.56 \pm 0.05$ & $0.57 \pm 0.05$ & $0.49 \pm 0.04$ & $0.55 \pm 0.04$ & $0.70 \pm 0.02$ & $0.67 \pm 0.04$ \\
Combined & $0.44 \pm 0.02$ & $0.68 \pm 0.05$ & $0.62 \pm 0.05$ & $0.63 \pm 0.03$ & $0.71 \pm 0.03$ & $0.59 \pm 0.02$ & $0.69 \pm 0.07$ & $0.68 \pm 0.05$ & $0.67 \pm 0.06$ \\
\hline
\end{tabular}

${ }^{\dagger}$ RNDVI, red normalized difference vegetation index; GNDVI, green normalized difference vegetation index; SR, simple ratio; WI, water index; NWI-1, normalized water index 1; NWI-2, normalized water index 2; NWI-3, normalized water index 3; NWI-4, normalized water index 4. 
ces. The correlated response was higher for the waterbased indices compared to the direct response for grain yield (Table 6). The ratio between correlated response for a primary trait via a secondary trait and the response to selection for the primary trait is a measure of the relative selection efficiency (Falconer, 1989). The relative selection efficiency of the SRI for grain yield revealed that indirect selection can be equally effective via SRI for grain yield selection (Table 6), especially with the water-based indices. The value of the relative selection efficiency depends on the genetic correlation between the direct and indirect traits and heritability of the traits (Falconer, 1989). We observed the relative selection efficiency was $>1$ for some of the water-based indices. Among the indices, the two newly developed water-based indices (NWI-3 and NWI4) consistently showed relative selection efficiencies of more than one in the two populations over different years and across years. Jackson (2001) indicated that an indirect selection trait should have higher heritability than the direct trait, and high genetic correlation with the direct trait. In addition, the indirect trait should have convenience and low costs of measurement. In the context of our study, greater genetic gain can be obtained by using the indirect traits (NWI-3 and NWI-4) than selecting for the direct trait (yield) itself. Strong genetic correlation, moderate to high heritability, higher correlated response than the direct response, and relative selection efficiency equal to or more than one for the water-based indices provided ample evidence for the potential of incorporating the water-based indices into a breeding program for obtaining greater genetic gain in grain yield.

\section{Selection of}

\section{Higher-Yielding Genotypes}

The percent of selected genotypes among the 25\% highest-yielding genotypes along with the percent yield difference between the harvested yield and predicted yield based on the linear regression equation between the SRI and yield are presented in Table 7. The water-based indices showed an advantage over the vegetation-based indices for selecting the higher-yielding genotypes compared to the widely used vegetation-based indices. Ball and Konzak
(1993) demonstrated the efficiency of normalized difference vegetation index in selecting higher-yielding genotypes under water nonlimiting conditions using two readings at the grain-filling stage, while Babar et al. (2006b) reported the higher efficiency of the near-infrared-based indices for grain yield selection under partially irrigated spring wheat environments. We have shown that the water-based indices are efficient in selecting higher-yielding genotypes in winter
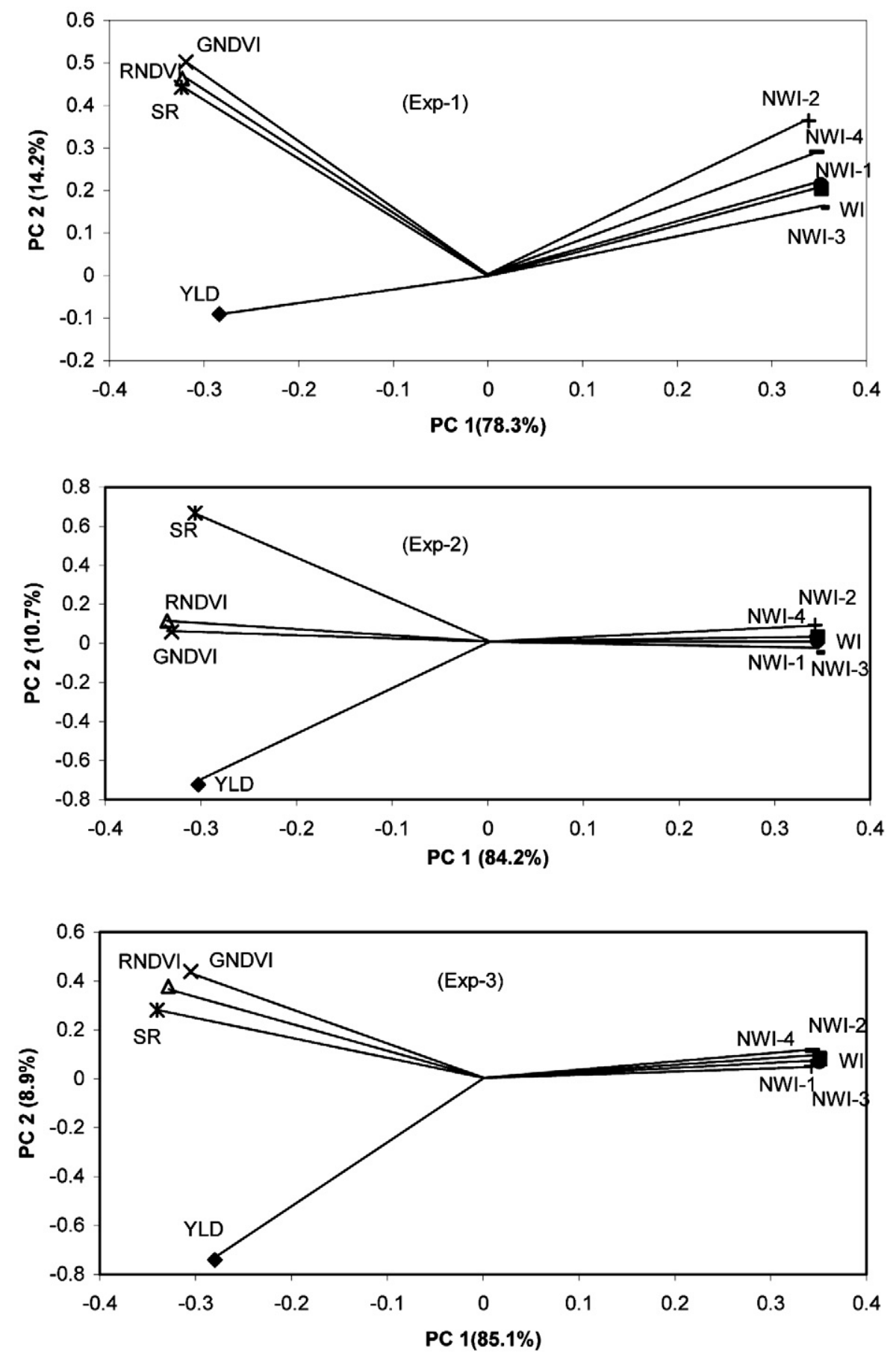

Figure 2. Two-dimensional distributions of coefficients of the first two principal components (PC) obtained by a multivariate analysis of different spectral reflectance indices and grain yield for three experiments. RNDVI, red normalized difference vegetation index; GNDVI, green normalized difference vegetation index; SR, simple ratio; WI, water index; NWI-1, normalized water index 1; NWI-2, normalized water index 2; NWI-3, normalized water index 3; NWI-4, normalized water index 4; YLD, yield. 
Table 6. Selection response $(R)$ for the spectral reflectance indices (SRI) and grain yield, correlated response $(C R)$ for grain yield using SRI, and relative selection efficiency $(C R / R)$ of the SRI for grain yield in two recombinant inbred populations.

\begin{tabular}{|c|c|c|c|c|c|c|c|c|c|c|}
\hline \multirow[t]{2}{*}{ Experiments } & \multirow{2}{*}{$\begin{array}{l}\text { Selection } \\
\text { parameter }^{\dagger}\end{array}$} & \multirow{2}{*}{$\begin{array}{l}\text { Grain } \\
\text { yield }\end{array}$} & \multicolumn{8}{|c|}{ Spectral reflectance indices ${ }^{\ddagger}$} \\
\hline & & & RNDVI & GNDVI & SR & WI & NWI-1 & NWI-2 & NWI-3 & NWI-4 \\
\hline \multicolumn{11}{|l|}{ Population 1} \\
\hline \multirow{3}{*}{ 2003-2004 } & $\mathrm{R}$ & 0.494 & 0.664 & 0.633 & 0.612 & 0.561 & 0.556 & 0.674 & 0.615 & 0.639 \\
\hline & $\mathrm{CR}$ & & 0.386 & 0.397 & 0.441 & -0.459 & -0.467 & -0.548 & -0.538 & -0.542 \\
\hline & $\mathrm{CR} / \mathrm{R}$ & & 0.782 & 0.803 & 0.892 & -0.928 & -0.945 & -1.108 & -1.088 & -1.092 \\
\hline \multirow[t]{3}{*}{ 2004-2005 } & $\mathrm{R}$ & 0.597 & 0.686 & 0.704 & 0.555 & 0.736 & 0.734 & 0.651 & 0.734 & 0.761 \\
\hline & $\mathrm{CR}$ & & 0.552 & 0.595 & 0.504 & -0.617 & -0.610 & -0.587 & -0.605 & -0.623 \\
\hline & $\mathrm{CR} / \mathrm{R}$ & & 0.925 & 0.996 & 0.844 & -1.033 & -1.022 & -0.983 & -1.013 & -1.043 \\
\hline \multirow[t]{3}{*}{ Across years } & $\mathrm{R}$ & 0.536 & 0.682 & 0.704 & 0.583 & 0.737 & 0.728 & 0.754 & 0.729 & 0.734 \\
\hline & $\mathrm{CR}$ & & 0.461 & 0.521 & 0.366 & -0.571 & -0.569 & -0.541 & -0.574 & -0.561 \\
\hline & $\mathrm{CR} / \mathrm{R}$ & & 0.860 & 0.971 & 0.681 & -1.065 & -1.060 & -1.006 & -1.071 & -1.047 \\
\hline \multicolumn{11}{|l|}{ Population 2} \\
\hline \multirow[t]{3}{*}{ 2003-2004 } & $\mathrm{R}$ & 0.531 & 0.466 & 0.426 & 0.461 & 0.634 & 0.560 & 0.579 & 0.635 & 0.639 \\
\hline & $\mathrm{CR}$ & & 0.281 & 0.314 & 0.305 & -0.495 & -0.468 & -0.467 & -0.560 & -0.539 \\
\hline & $\mathrm{CR} / \mathrm{R}$ & & 0.529 & 0.591 & 0.575 & -0.933 & -0.882 & -0.879 & -1.054 & -1.052 \\
\hline \multirow[t]{3}{*}{ 2004-2005 } & $\mathrm{R}$ & 0.517 & 0.603 & 0.589 & 0.576 & 0.573 & 0.484 & 0.566 & 0.693 & 0.675 \\
\hline & $\mathrm{CR}$ & & 0.371 & 0.366 & 0.346 & -0.476 & -0.458 & -0.474 & -0.533 & -0.550 \\
\hline & $\mathrm{CR} / \mathrm{R}$ & & 0.717 & 0.707 & 0.669 & -0.920 & -0.885 & -0.915 & -1.031 & -1.063 \\
\hline \multirow[t]{3}{*}{ Across years } & $\mathrm{R}$ & 0.403 & 0.547 & 0.615 & 0.626 & 0.613 & 0.430 & 0.670 & 0.589 & 0.594 \\
\hline & $\mathrm{CR}$ & & 0.273 & 0.292 & 0.278 & -0.410 & -0.412 & -0.373 & -0.466 & -0.428 \\
\hline & $\mathrm{CR} / \mathrm{R}$ & & 0.678 & 0.723 & 0.690 & -1.017 & -1.023 & -0.925 & -1.154 & -1.061 \\
\hline
\end{tabular}

†Selection parameters were estimated based on the mean values of the SRI from heading and grain-filling stages.

fRNDVI, red normalized difference vegetation index; GNDVI, green normalized difference vegetation index; SR, simple ratio; WI, water index; NWI-1, normalized water index 1; NWI-2, normalized water index 2; NWI-3, normalized water index 3; NWI-4, normalized water index 4.

wheat rain-fed environments. Up to $83 \%$ of the top $25 \%$ highest-yielding genotypes (around 5.0 tons $\mathrm{ha}^{-1}$ ) were detected with the normalized water indices (Table 7). From the percent yield difference data between actual yield and predicted yield, it is evident that water-based indices showed a close approximation of actual grain yield. These data indicate that the water-based indices, especially the newly developed NWI-3 and NWI-4, have potential as efficient indirect selection tools for identifying superior genotypes for grain

Table 7. The percentage of selected genotypes among the $25 \%$ highestyielding genotypes based on the spectral reflectance indices (SRI), and percent yield difference (values in parentheses) between yield per se and yield estimates based on SRI in two recombinant inbred populations.

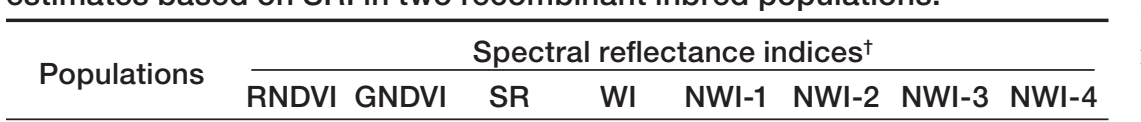

Population 1

Year 2003-2004 67 (7.0) $67(5.6) 67(4.6) \quad 67(3.6) 67$ (3.6) $67(4.4) 67(3.5) \quad 67(4.1)$ Year 2004-2005 $67(2.2) \quad 50(1.9) \quad 50(5.8) \quad 67(1.3) \quad 67(1.4) \quad 67(1.1) \quad 67(1.7) \quad 67(1.4)$ Combined $\quad 67(3.4) 67(2.4) \quad 50(5.4) \quad 83(2.2) \quad 67(2.3) \quad 83(2.6) \quad 83(2.2) \quad 83(2.7)$

Population 2

Year 2003-2004 $33(7.5) \quad 50(6.2) \quad 33(6.0) \quad 50(4.2) \quad 50(4.3) \quad 33(4.7) \quad 67(4.2) \quad 67(4.5)$ Year 2004-2005 $50(7.3) \quad 33(7.9) \quad 50(6.7) \quad 50(6.2) \quad 50(6.1) \quad 50(6.1) \quad 67(6.2) \quad 67(6.3)$

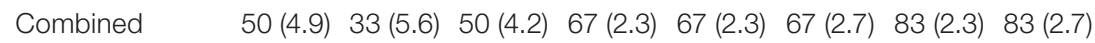

${ }^{t} \mathrm{RNDVI}$, red normalized difference vegetation index; GNDVI, green normalized difference vegetation index; SR, simple ratio; WI, water index; NWI-1, normalized water index 1; NWI-2, normalized water index 2; NWI-3, normalized water index 3; NWI-4, normalized water index 4. yield in a wheat breeding programs, especially in the Great Plains winter wheat rain-fed environments.

\section{CONCLUSIONS}

The genetic basis for the indirect selection of winter higher genetic correlations with grain yield compared to RNDVI, GNDVI, and SR. The heritability estimates were also higher for the water-based indices than for grain yield itself. Response to selection for the two newly developed indices (NWI-3 and NWI-4) was higher than the direct response for grain yield. The correlated response of these indices for grain yield was equal to or higher than the direct response for grain yield, and the relative selection efficiency was always $>1$. These newly developed indices detected a significant proportion of the highest-yielding genotypes. Based on these genetic parameters, it seems probable that significant genetic gains can be obtained through the use of the NWI-3 and NWI-4 as indirect selection tools for grain yield improvement in winter wheat breeding programs in Great Plains rain-fed environments. 


\section{References}

Aparicio, N., D. Villegas, J. Casadesus, J.L. Araus, and C. Royo. 2000. Spectral vegetation indices as nondestructive tools for determining durum wheat yield. Agron. J. 92:83-91.

Araus, J.L., J. Casadesus, and J. Bort. 2001. Recent tools for the screening of physiological traits determining yield. p. 59-77. In M.P. Reynolds et al. (ed.) Application of physiology in wheat breeding. CIMMYT, Mexico, DF.

Atlin, G.N., and K.J. Frey. 1989. Predicting the relative effectiveness of direct versus indirect selection for oat yield in three types of stress environments. Euphytica 44:137-142.

Babar, M.A., M.P. Reynolds, M. van Ginkel, A.R. Klatt, W.R. Raun, and M.L. Stone. 2006a. Spectral reflectance indices as a potential indirect selection criteria for wheat yield under irrigation. Crop Sci. 46:578-588.

Babar, M.A., M. van Ginkel, A.R. Klatt, B. Prasad, and M.P. Reynolds. 2006b. The potential of using spectral reflectance indices to estimate yield in wheat grown under reduced irrigation. Euphytica 150:155-172.

Ball, S.T., and C. Konzak. 1993. Relationship between grain yield and remotely sensed data in wheat breeding experiments. Plant Breed. 110:277-282.

Baret, F., and G. Guyot. 1991. Potentials and limits of vegetation indices for LAI and APAR estimation. Remote Sens. Environ. 35:161-173.

Calhoun, D.S., G. Gebeyehou, A. Miranda, S. Rajaram, and M. van Ginkel. 1994. Choosing evaluation environments to increase wheat grain yield under drought conditions. Crop Sci. 34:673-678.

Elliott, G.A., and K.L. Regan. 1993. Use of reflectance measurements to estimate early cereal biomass production on sandplain soils. Aust. J. Exp. Agric. 33:179-183.

Falconer, D.S. 1989. Introduction to quantitative genetics. 3rd ed. Longman Scientific and Technical, New York.

Filella, I., L. Serrano, J. Serra, and J. Peñuelas. 1995. Evaluating wheat nitrogen status with canopy reflectance indices and discriminant analysis. Crop Sci. 35:1400-1405.

Gallais, A. 1984. Use of indirect selection in plant breeding. p. 45-60. In W. Lange et al. (ed.) 10th Eucarpia Congress: Efficiency in plant breeding. 19-24 June 1983. Pudoc, Wageningen, the Netherlands.

Gitelson, A.A., Y.J. Kaufman, and M.N. Merzylak. 1996. Use of a green channel in remote sensing of global vegetation from EOS-MODIS. Remote Sens. Environ. 58:289-298.

Jackson, P., M. Robertson, M. Copper, and G. Hammer. 1996. The role of physiological understanding in plant breeding, from a breeding perspective. Field Crops Res. 49:11-37.

Jackson, P.A. 2001. Direction of physiological research in breeding: Issues from a breeding perspective. p. 11-16. In M.P. Reynolds et al. (ed.) Application of physiology in wheat breeding. CIMMYT, Mexico, DF.

Knipling, E.B. 1970. Physical and physiological basis for the reflectance of visible and near- infrared radiation from vegetation. Remote Sens. Environ. 1:155-159.

Ma, B.L., L.M. Dwyer, C. Costa, E.L. Cober, and M.J. Morrison.
2001. Early prediction of soybean yield from canopy reflectance measurements. Agron. J. 93:1227-1234.

Peñuelas, J., and I. Filella. 1998. Visible and near-infrared reflectance techniques for diagnosing plant physiological status. Trends Plant Sci. 3:151-156.

Peñuelas, J., I. Filella, C. Biel, L. Serrano, and R. Save. 1993. The reflectance at the $950-970 \mathrm{~nm}$ region as an indicator of plant water status. Int. J. Remote Sens. 14:1887-1905.

Peñuelas, J., R. Isla, I. Filella, and J.L. Araus. 1997. Visible and near-infrared reflectance assessment of salinity effects on barley. Crop Sci. 37:198-202.

Prasad, B., B.F. Carver, M.L. Stone, M.A. Babar, W.R. Raun, and A.R. Klatt. 2007. Potential use of spectral reflectance indices as a selection tool for grain yield in winter wheat under Great Plains conditions. Crop Sci. 47:1426-1440.

Price, J.C., and W.C. Bausch. 1995. Leaf area index estimation from visible and near-infrared reflectance data. Remote Sens. Environ. 52:55-65.

Raun, W.R., J.B. Solie, G.V. Johnson, M.L. Stone, E.V. Lukina, W.E. Thomason, and J.S. Schepers. 2001. In-season prediction of potential grain yield in winter wheat using canopy reflectance. Agron. J. 93:131-138.

Reynolds, M.P., S. Rajaram, and K.D. Sayre. 1999. Physiological and genetic changes of irrigated wheat in the post-green revolution period and approaches for meeting projected global demand. Crop Sci. 39:1611-1621.

Reynolds, M.P., R.M. Trethowan, M. van Ginkel, and S. Rajaram. 2001. Application of physiology in wheat breeding. p. 210. In M.P. Reynolds, J.I. Ortiz-Monasterio, and A. McNab (ed.) Application of physiology in wheat breeding. CIMMYT, Mexico, DF.

Richards, R.A. 1982. Breeding and selecting for drought resistant wheat. p. 303-316. In Drought resistance in crops with emphasis on rice. IRRI, Manila, Philippines.

Richards, R.A. 1996. Defining selection criteria to improve yield under drought. Plant Growth Regul. 20:157-166.

Royo, C., N. Aparicio, D. Villegas, J. Casadesus, P. Monneveux, and J.L. Araus. 2003. Usefulness of spectral reflectance indices as durum wheat yield predictors under contrasting Mediterranean conditions. Int. J. Remote Sens. 24:4403-4419.

SAS Institute. 2001. The SAS system for windows, version 8.2. SAS Inst., Cary, NC.

Serrano, L., I. Filella, and J. Peñuelas. 2000. Remote sensing of biomass and yield of winter wheat under different nitrogen supplies. Crop Sci. 40:723-731.

Sinebo, W., R. Gretzmacher, and A. Edelbauer. 2002. Environment of selection for grain yield in low fertilizer input in barley. Field Crops Res. 74:151-162.

Tucker, C.J. 1979. Red and photographic linear combinations for monitoring vegetation. Remote Sen. Environ. 8:127-150.

Wiegand, C.L., and A.J. Richardson. 1990. Use of spectral vegetation indices to infer leaf area, evapotranspiration, and yield: II. Results. Agron. J. 82:630-636.

Zadoks, J.C., T.T. Chang, and C.F. Konzak. 1974. A decimal code for the growth stages of cereals. Weed Res. 14:415-421. 